\title{
ADDITIONAL EFFECTS OF DULOXETINE IN RELATION TO EXERCISE ON SARCOPENIA ASSOCIATED WITH KNEE OSTEOARTHRITIS: A RANDOMIZED CLINICAL TRIAL
}

Marielle Moro da Silva ${ }^{1, *}$, Kaleb Pinto Spannenberger ${ }^{1}$, Paula Schoproni Cardoso ${ }^{1}$, Julia Bueno ${ }^{1}$, Mateus Espíndola de Moraes ${ }^{1}$, Leonardo Peterson dos Santos², Rafaela Cavalheiro do Espírito Santo², Andrese Aline Gasparin², Vanessa Hax², Rafael Mendonça da Silva Chakr ${ }^{1,2}$

1. Universidade Federal do Rio Grande do Sul, Porto Alegre (RS), Brazil. 2. Hospital de Clínicas de Porto Alegre, Porto Alegre (RS), Brazil.

*Corresponding author: mariellemorosilva@gmail.com

\section{BACKGROUND}

The effects of duloxetine on sarcopenia are unknown in older adults with painful knee osteoarthritis (KOA) and lower physical performance, when added to standard exercise therapy. To study the additional effects of duloxetine on physical performance, muscle mass and muscle strength of individuals with KOA and lower physical performance treated with a home-based exercise program (HE).

\section{MATERIALS AND METHODS}

In a randomized, double-blind, placebo-controlled, 12-week trial, we assigned older adults with painful KOA and lower physical performance in a $1: 1$ ratio and blocks of 4 to receive duloxetine $(60 \mathrm{mg} / \mathrm{dL}$ ) or matching placebo, in addition to standard $\mathrm{HE}$ therapy. The primary endpoint at week 12 was a difference in physical performance of $>0.8$ in short physical performance battery (SPPB) between groups. Secondary endpoints included 12-week changes in muscle mass by dual-energy X-ray absorptiometry (appendicular skeletal muscle mass index - ASMI), strength by knee extension maximal isometric voluntary contraction (KE) and pain by visual analog scale (VAS).

\section{RESULTS}

Between March 2017 and January 2020, 24 patients (12 per group) were included: 77.2\% were women, 79.2\% Caucasian, on average $64.3 \pm 6.8$ years of age. After 12 weeks, $\mathrm{HE}+$ placebo group performed more minutes of HE than HE + duloxetine group [692 (IQR 300 to 1,120) vs. 310 (IQR 210 to 543), p = 0.015] and both groups significantly improved SPPB [HE + duloxetine: 1.52 (CI95\% 0.53 to 2.51) and HE + placebo: 2.00 (CI95\% 1.23 to 2.77)], with no differences between them ( $p=0.456)$. Only $\mathrm{HE}+$ duloxetine group improved the balance component of SPPB [0.27 (Cl95\% 0.01 to 0.54)] and pain VAS [-2.41 (CI95\% -3.82 to -0.99)], while only HE + placebo group improved KE [11.8 kg (Cl95\% 4.3 to 19.2)] and ASMI [0.4 kg/m2 (Cl95\% 0.0 to 0.9)]. Twelve-week variations in pain VAS and ASMI correlated only in HE + placebo group ( $r s=0.821 ; p=0.023$ ). Two individuals in each group withdrew from the study due to adverse events.

\section{CONCLUSION}

Duloxetine was not superior to placebo in increasing physical performance of KOA patients treated with home-based exercise. Duloxetine seems to have an additional benefit in relation to home-based exercise on pain and balance. Also, duloxetine appears to impair the benefits of exercise on strength and muscle mass, possibly by reducing the adherence to the home-based exercise program.

\section{FUNDING}

FIPE and SBR. 


\section{ACKNOWLEDEGMENTS}

Adriana Brentano, Franciele Menegat and PhD Penélope Palominos.

\section{REFERENCES}

1. De Ceuninck F, Fradin A, Pastoureau P. Bearing arms against osteoarthritis and sarcopenia: when cartilage and skeletal muscle find common interest in talking together. Drug Discov Today. 2014;19(3):305-11. https://doi.org/10.1016/j.drudis.2013.08.004

2. Park HM, Kim HJ, Lee B, Kwon M, Jung SM, Sang-Won Lee S-W, et al. Decreased muscle mass is independently associated with knee pain in female patients with radiographically mild osteoarthritis: a nationwide cross-sectional study (KNHANES 2010-2011). Clin Rheumatol 2018;37(5):133340. https://doi.org/10.1007/s10067-017-3942-9 